\title{
CYTOLOGICAL PATTERNS OF THYROID LESIONS: A HOSPITAL-BASED STUDY
}

\author{
Dharmakanta Kumbhakar ${ }^{1}$
}

${ }^{1}$ AssociateProfessor, Department of Pathology, Tezpur Medical College and Hospital, Tezpur, Sonitpur, Assam.

ABSTRACT
BACKGROUND
Diverse cytological patterns of thyroid lesions may occur in the thyroid gland for its various diseases. The thyroid lesions may be non-
neoplastic lesions or neoplastic lesions. Most of the thyroid lesions clinically present as thyroid swellings either as thyroid nodules or as diffuse
enlargement of the gland itself. Fine Needle Aspiration Cytology (FNAC) is a rapid, easy to perform, minimally invasive and cost-effective first line
high diagnostic accuracy test for cytological evaluation of thyroid lesions with minimum complications. The thyroid gland is easily accessible for
Fine Needle Aspiration (FNA) procedure due to its superficial location. The accurate cytological diagnosis of the thyroid lesions can direct the
treatment modalities of the lesions and reduce unnecessary thyroid surgeries.

\section{AIMS AND OBJECTIVES}

A hospital-based study to determine the cytological patterns of thyroid lesions by FNAC and to correlate the cytological and histopathological diagnosis wherever possible.

\section{MATERIALS AND METHODS}

The study was based on "FNAC analysis of 100 thyroid lesions presented as thyroid swellings" (study group) in the period of two (02) years from June 1, 2014, to May 31, 2016, in the cytopathology section of the Pathology Department of Tezpur Medical College and Hospital, Tezpur, Assam. Histopathological correlation was done in the surgically treated thyroid lesions of the study group.

\section{RESULTS AND OBSERVATIONS}

Female patients (87) comprised majority of thyroid lesions (87.00\%), while male patients (13) were only $13.00 \%$ of thyroid lesions with a male and female patients' ratio of 6.69:1 in the study group. Maximum patients with thyroid lesions, irrespective of sex in the study group were in the age group of 31-40 years. The youngest patient in the study group was a 7 years old girl diagnosed as lymphocytic thyroiditis and the oldest patient in the study group was a 73 years old female diagnosed as colloid goitre. Out of 100 thyroid lesions in the study, FNA smears of 05 thyroid lesions were inadequate for cytological reporting either due to inadequate aspirated materials or haemorrhagic smears. Out of remaining 95 thyroid lesions in the study, which had adequate FNA smears for cytological reporting, there were 84 (88.42\%) non-neoplastic lesions and 11 $(11.58 \%)$ neoplastic lesions with a non-neoplastic and neoplastic ratio of 7.64:1. Colloid goitres were the commonest non-neoplastic thyroid lesions in the study. Out of the 8 thyroid lesions diagnosed as thyroiditis in the study, granulomatous thyroiditis (04) were the commonest. Benign tumours (6.32\%) were found to be more common than malignant ones (4.21\%) with a benign and malignant tumours ratio of 1.50:1 in the study Follicular neoplasms were the commonest benign tumours and papillary thyroid carcinomas were the commonest malignant tumours amongst the studied thyroid lesions. One thyroid lesion of medullary carcinoma was also diagnosed. Among all thyroid lesions in the study, with adequate FNA smears for cytological reporting, 70 (73.68\%) thyroid lesions were goitres with or without secondary changes, 06 (6.32\%) thyroid lesions were benign neoplasms, $01(1.05 \%)$ thyroid lesion was suspicious and $04(4.21 \%)$ thyroid lesions were malignant neoplasms. FNAC studies done only on 15 thyroid lesions in the study group were available for histopathological studies and showed $93.33 \%$ diagnostic accuracy. The histopathological findings of that 15 thyroid lesions showed 11 non-neoplastic $(73.33 \%)$ and $04(26.67 \%)$ neoplastic lesions. On comparison of FNAC and histopathology study reports of these 15 thyroid lesions, histopathology confirmed all the 11 non-neoplastic lesions (10 were simple colloid goitres and 1 thyroglossal cyst) and 3 out of 4 neoplastic lesions diagnosed on FNAC. Out of 3 thyroid lesions diagnosed as follicular neoplasms on FNAC, 2 thyroid lesions confirmed the diagnosis, but one was confirmed as follicular variant of papillary carcinoma on histopathology. One thyroid lesion diagnosed as papillary carcinoma on FNAC was confirmed on histopathology.

\section{DISCUSSION}

Today, FNAC is practiced worldwide for rapid and accurate preoperative diagnosis of thyroid lesions. There are several studies regarding cytological evaluation of thyroid lesions by FNA and literatures claiming the usefulness of thyroid cytology. This study was a hospital-based study that described the cytological patterns of thyroid lesions that encountered in this institute within the study period and histopathological diagnosis comparison wherever possible. The results and observations of this study were most comparable with the previous studies by other researchers The limitation of the study was that due to absence of representative aspirated materials of 05 thyroid lesions couldn't be diagnosed in the appropriate manner. FNAC diagnoses of only 15 thyroid lesions were available for histopathological study. All patients performed FNAC for thyroid lesions during the study period in our institute couldn't be followed up, probably these patients attended other centres later.

\section{CONCLUSION}

FNAC has high sensitivity in cytological diagnosis of thyroid lesions and accurate cytological diagnosis may be considered as a primary line of investigation of thyroid lesions and its management. Due to its high accuracy, sensitivity and specificity, the study established its usefulness for proper line of management of the patients with thyroid lesions.

\section{KEYWORDS}

Thyroid Nodule, Colloid Goitre, Follicular Neoplasm, Papillary Carcinoma, Medullary Carcinoma, Thyroidectomy, Thyroiditis, Histopathological, Thyroglossal Cyst, Granulomatous Thyroiditis, FNAC.

HOW TO CITE THIS ARTICLE: Kumbhakar D. Cytological patterns of thyroid lesions: a hospital-based study. J. Evolution Med. Dent. Sci. 2016;5(65):4661-4665, DOI: 10.14260/jemds/2016/1062

Financial or Other, Competing Interest: None.

Submission 21-06-2016, Peer Review 29-07-2016,

Acceptance 05-08-2016, Published 13-08-2016.

Corresponding Author:

Dr. Dharmakanta Kumbhakar,

Associate Professor,

Department of Pathology,

Tezpur Medical College and Hospital,

Tezpur, Sonitpur, Assam

E-mail: drkdharmakanta@yahoo.com

DOI: $10.14260 /$ jemds/2016/1062

\section{INTRODUCTION}

Diverse cytological patterns of thyroid lesions may occur in the thyroid gland for its various diseases.[1]

The thyroid lesions may be non-neoplastic lesions or neoplastic lesions. The non-neoplastic lesions of thyroid gland include: goitre, dyshormonogenetic goitre, thyroiditis, hyperplastic nodule, simple cyst and thyroglossal cyst. Follicular neoplasm, Hurthle cell neoplasm, papillary carcinoma, medullary carcinoma and anaplastic carcinoma are included in the neoplastic entities of the thyroid gland. 
Most of the thyroid lesions clinically present as thyroid swellings, either as thyroid nodules or as diffuse enlargement of the gland itself. Thyroid nodules are one of the most common clinical presentation with an annual incidence being $4 \%$ of general population (Kini SR, 1999). The majority of them are being benign. ${ }^{2]}$

The clinical assessment of thyroid nodules are done by considering their sizes, textures, nodularities, fixation and tenderness. Thyroid cancers occur in a small proportion of patients with thyroid nodules, ranging from $5-20 \%$ for the general population and from $18-30 \%$ for the population exposed to ionising radiation. ${ }^{[3,4,5]}$ Children and adolescents should not be excluded because they may also harbour malignant tumours. ${ }^{[6]}$

Fine Needle Aspiration Cytology (FNAC) is a rapid, easy to perform, minimally invasive and cost-effective first line high diagnostic accuracy test for cytological evaluation of thyroid lesions with minimum complications. ${ }^{[7,8]}$ The thyroid gland is easily accessible for Fine Needle Aspiration (FNA) procedure due to its superficial location. ${ }^{[9.10]}$ The accurate cytological diagnosis of the thyroid lesions can direct the treatment modalities of the lesions and reduce unnecessary thyroid surgeries.[11.12]

Today, FNAC of thyroid lesions are practiced worldwide.[13] Rapid preoperative assessment and accurate diagnosis of fine needle aspirated smears have become increasingly popular due to the global trend in reducing healthcare costs.[14,15,16] The primary objective of FNAC of the thyroid lesions is to select those patients who require surgeries for neoplastic thyroid disorders from those who have functional or inflammatory abnormalities and who can be followed clinically or treated medically.[17,18] Statistical evidence strongly suggests that the use of fine needle aspiration biopsy has markedly reduced the numbers of thyroidectomies whereas the proportion of carcinomas in the surgically treated population has increased significantly.[19]

\section{AIMS AND OBJECTIVES}

The hospital-based study was undertaken to identify the cytological patterns of thyroid lesions by FNAC and to correlate the cytological and histopathological diagnosis wherever possible.

\section{MATERIALS AND METHODS}

The study was carried out on 100 patients of thyroid lesions of all age groups, irrespective of sex, presented as thyroid swellings for FNAC analysis of the lesions in the cytopathology section of Pathology Department of Tezpur Medical College and Hospital, Tezpur, Assam, in the period of two (02) years from June 1, 2014, to May 31, 2016, (study group). Fine Needle Aspirations (FNA) were done on the thyroid lesions to collect specimens for cytological evaluation using 23/24 gauge disposable needles attached with 10/20 $\mathrm{mL}$ airtight disposable syringes according standard operative procedure. Specimens were collected by to and fro motions applying negative pressure. FNA procedures were performed after detailed clinical history, physical examination and thyroid function tests of the patients. The aspirated materials from the thyroid lesions were smeared onto clean grease-free glass slides, air dry smears for May-Grunwald Giemsa (MGG) staining and 95\% alcohol fixed smears for Papanicolaou staining. Ziehl-Neelsen staining were performed wherever required. In case of cystic thyroid lesions, after aspiration of fluids from the thyroid cysts, the lesions were again aspirated for materials. The fluids were centrifuged and smears were made from the sediments. Cytological diagnosis of the thyroid lesions were done and recorded after proper cytomorphological evaluation of the smears and clinical findings. The cytological results were categorised into three groups: Inadequate (Inconclusive), non-neoplastic and neoplastic. Neoplastic lesions were again classified as benign, suspicious and malignant. The cytological diagnosis were correlated with histopathological diagnosis wherever possible.

The biopsy specimens of the operated thyroid lesions included in the study were received in $10 \%$ formalin from the operation theatre of ENT Department of the institute. The specimens were observed grossly in the histopathology section of Pathology Department of the institute and findings were noted in the note sheets. The biopsy thyroid tissues were then sectioned and processed in the conventional manner as described in the "Theory and Practice of Histological Techniques", $5^{\text {th }}$ edition, 2002, edited by J D Bancroft and Marilyn Gamble.[20] After completion of the processing, they were made in paraffin blocks and cut in rotatory microtome of about $3-5 \mu$ thickness. The sections were stained by conventional Haematoxylin and Eosin staining, mounted in DPX and examined under microscope. Their special features were noted and a histopathological diagnosis of the studied thyroid lesions were done to correlate with their FNAC diagnosis. All the records and entries were double checked by the author.

\section{RESULTS AND OBSERVATIONS}

The study included a total of 100 patients that underwent FNAC for evaluation of thyroid lesions presented as thyroid swellings in the cytopathology section of Pathology Department of Tezpur Medical College and Hospital, Tezpur, Assam, during the study period. Patients with thyroid lesions of all age groups and both sexes attended our institute during the study period were included in the study.

Table 1 shows that female patients (87) comprised majority of thyroid lesions $(87.00 \%)$, while male patients (13) were only $13.00 \%$ of thyroid lesions with a male and female patients' ratio of 6.69:1 in the study group (Cite Figure-1). The Table 1 also shows the age distribution of patients with thyroid lesions included in the study. The youngest patient in the study group was a 7 years old girl diagnosed as inflammatory lesion of the thyroid gland (Lymphocytic thyroiditis) and the oldest patient in the study group was a 73 years old female diagnosed as colloid goitre. Maximum patients with thyroid lesions, irrespective of sex in the study group were in the age group of 31-40 years.

Out of 100 thyroid lesions in the study, FNA smears of 05 thyroid lesions were inadequate for cytological reporting either due to inadequate aspirated materials or haemorrhagic smears. So, that 05 thyroid lesions in the study were categorised as Inconclusive. Depending on the cytomorphological features of the adequate FNA smears for cytological reporting of remaining 95 thyroid lesions in the study were classified into two categories: non-neoplastic and neoplastic. The neoplastic lesions were again classified as benign, suspicious and malignant. The distribution of cytological patterns of all the studied thyroid lesions are shown in Table 2. 
Out of the remaining 95 thyroid lesions in the study, which had adequate FNA smears for cytological reporting, there were $84(88.42 \%)$ non-neoplastic lesions and 11 (11.58\%) neoplastic lesions with a non-neoplastic and neoplastic ratio of 7.64:1 (Cite Figure 2).

Among the all thyroid lesions in the study, with adequate FNA smears for cytological reporting, 70 (73.68\%) thyroid lesions were goitres with or without secondary changes, 06 $(6.32 \%)$ thyroid lesions were benign neoplasms, $01(1.05 \%)$ thyroid lesion was suspicious and $04(4.21 \%)$ thyroid lesions were malignant neoplasms. Colloid goitres were the commonest non-neoplastic thyroid lesions in the study. Out of the 8 thyroid lesions diagnosed as thyroiditis in the study, granulomatous thyroiditis (04) were the commonest.

Benign tumours $(6.32 \%)$ were found to be more common than malignant ones $(4.21 \%)$ with a benign and malignant tumours ratio of 1.50:1 in the study. All the 6 thyroid lesions of benign tumours in the study were follicular neoplasms. The suspicious thyroid lesion was reported as follicular neoplasm and papillary thyroid carcinomas were the commonest malignant tumours detected in the study. One case of medullary carcinoma was also diagnosed in the study.

Of these 95 patients with thyroid lesions, only 15 patients with thyroid lesions underwent surgical interventions and histopathological examinations of the thyroidectomy specimens were performed. The histopathological findings of these 15 thyroid lesions that underwent surgery were 11 non-neoplastic (73.33\%) and $04(26.67 \%)$ neoplastic in nature.

When the study reports of FNAC and histopathology of these 15 thyroid lesions were compared, histopathology confirmed all the 11 non-neoplastic lesions and 3 out of 4 neoplastic lesions diagnosed on FNAC. The entire 10 nonneoplastic lesions were simple colloid goitres both on FNAC and histopathological examination. One case of thyroglossal cyst diagnosed in FNAC was diagnosed as same on histopathological examination. Out of 3 thyroid lesions diagnosed as follicular neoplasms (Cite Figure 3) on FNAC, which were operated, 2 thyroid lesions confirmed the diagnosis, but one was confirmed as follicular variant of papillary carcinoma on histopathology. One operated thyroid lesion diagnosed as papillary carcinoma (Cite Figure 4) on FNAC was confirmed on histopathology (Cite Figure 5). The result accuracy (diagnostic accuracy) in the study from the available histopathological correlation was 93.33\%. [Cite Table-3: Comparison between Cytology and Histopathology of Thyroid Lesions in the Study $(n=14)]$. Other patients of thyroid lesions included in the study group for FNAC analysis lost the followup for histopathological correlation.

\begin{tabular}{|c|c|c|c|}
\hline $\begin{array}{c}\text { Age } \\
\text { Group } \\
\text { (Years) }\end{array}$ & Male & Female & $\begin{array}{c}\text { Total (No. } \\
\text { and \%) }\end{array}$ \\
\hline $0-10$ & Nil & 01 & $01(01 \%)$ \\
\hline $11-20$ & 01 & 05 & $06(06 \%)$ \\
\hline $21-30$ & 03 & 24 & $27(27 \%)$ \\
\hline $31-40$ & 04 & 39 & $43(43 \%)$ \\
\hline $41-50$ & 03 & 07 & $10(10 \%)$ \\
\hline $51-60$ & 02 & 05 & 07 (07\%) \\
\hline $60-70$ & 00 & 04 & $04(04 \%)$ \\
\hline \multirow[t]{2}{*}{$70+$} & 00 & 02 & $02(02 \%)$ \\
\hline & $\begin{array}{c}13 \\
(13.00 \%)\end{array}$ & $\begin{array}{c}87 \\
(87.00 \%)\end{array}$ & $\begin{array}{c}100 \\
(100 \%)\end{array}$ \\
\hline & $\begin{array}{r}\text { e and Sex L } \\
\text { Les }\end{array}$ & $\begin{array}{l}\text { ibution of } \\
\text { s in the Stu }\end{array}$ & th Thyroid \\
\hline
\end{tabular}

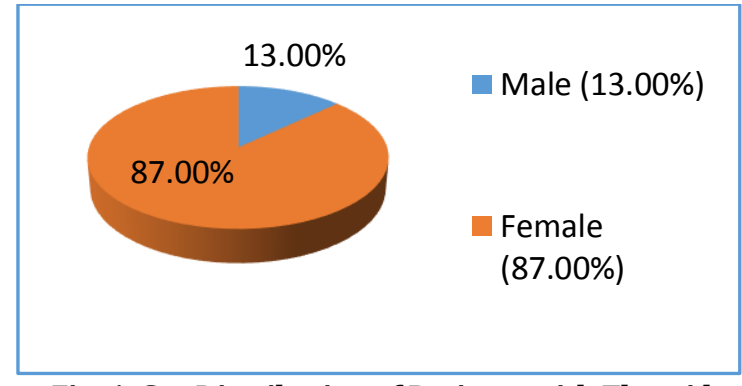

Fig. 1: Sex Distribution of Patients with Thyroid Lesions in the Study

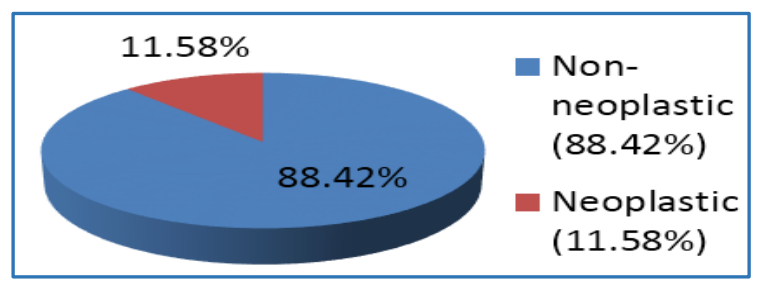

Fig. 2: Percentage of Non-Neoplastic and Neoplastic Thyroid Lesions in the Study

\begin{tabular}{|l|c|c|c|}
\hline \multicolumn{1}{|c|}{ Cytology } & Male & Female & Total \\
\hline Non-Neoplastic & 09 & 75 & $84(88.42 \%)$ \\
1. Goitre & 06 & 64 & $70(73.68 \%)$ \\
(i) Simple Colloid Goitre. & 03 & 41 & $44(46.32 \%)$ \\
(ii) Colloid Goitre with Cystic & 02 & 16 & $18(18.94 \%)$ \\
Changes. & & & \\
(iii) Adenomatous Goitre. & 01 & 07 & $08(8.42 \%)$ \\
2. Cystic lesion & 02 & 04 & $06(6.32 \%)$ \\
(i) Simple Cyst. & 02 & 03 & $05(5.27 \%)$ \\
(ii) Thyroglossal cyst. & 00 & 01 & $01(1.05 \%)$ \\
3.Thyroiditis & 01 & 07 & $08(8.42 \%)$ \\
(i) Hashimoto's. & 01 & 02 & $03(3.16 \%)$ \\
(ii) Granulomatous. & 00 & 04 & $04(4.21 \%)$ \\
(iii) Lymphocytic. & 00 & 01 & $01(1.05 \%)$ \\
\hline Neoplastic & 03 & 08 & $11(11.58 \%)$ \\
(A) Benign & 02 & 04 & $06(6.32 \%)$ \\
1. Follicular Neoplasm. & 02 & 04 & $06(6.32 \%)$ \\
(B) Suspicious & 00 & 01 & $01(1.05 \%)$ \\
1. Follicular Neoplasm. & 00 & 01 & $01(1.05 \%)$ \\
(C) Malignant & 01 & 03 & $04(4.21 \%)$ \\
1. Papillary Carcinoma. & 00 & 03 & $03(3.16 \%)$ \\
2. Medullary Carcinoma. & 01 & 00 & $01(1.05 \%)$ \\
\hline Inconclusive & 01 & 04 & $05(5.00 \%)$ \\
1. Inadequate Material. & 00 & 01 & $01(1.00 \%)$ \\
2. Haemorrhagic. & 01 & 03 & $04(4.00 \%)$ \\
\hline Table 2: Distribution of Cytological Patterns of Thyroid \\
\end{tabular}

\begin{tabular}{|c|c|c|c|}
\hline Lesion & Pathology & Cytology & Histopathology \\
\hline $\begin{array}{c}\text { Non- } \\
\text { Neoplastic } \\
\text { (n=11) }\end{array}$ & $\begin{array}{c}\text { Colloid } \\
\text { Goitre }\end{array}$ & 10 & 10 \\
\cline { 2 - 4 } & $\begin{array}{c}\text { Cystic } \\
\text { Lesion }\end{array}$ & 01 & 01 \\
\hline \multirow{2}{*}{$\begin{array}{c}\text { Neoplastic } \\
\text { (n=4) }\end{array}$} & $\begin{array}{c}\text { Follicular } \\
\text { Neoplasm }\end{array}$ & 03 & 02 \\
\cline { 2 - 4 } & $\begin{array}{c}\text { Papillary } \\
\text { Carcinoma }\end{array}$ & 01 & 01 \\
\hline Table 3: Comparison between Cytology and Histopathology \\
of Thyroid Lesions in the Study (n=14)
\end{tabular}




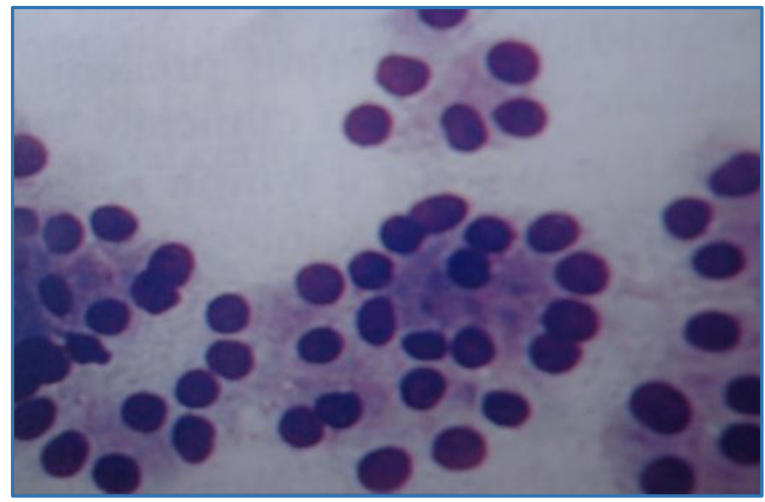

Fig. 3: Photomicrograph showing FNAC from Follicular Neoplasm (MGG Stain)

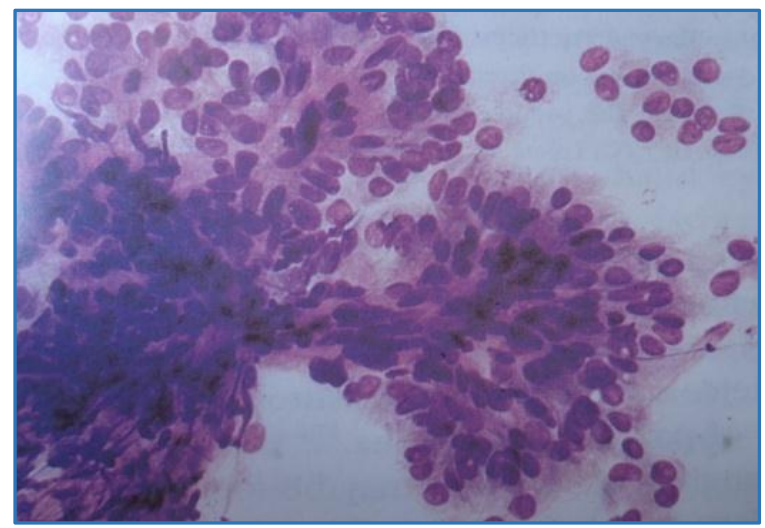

Fig. 4: Photomicrograph showing FNAC from Papillary Carcinoma Thyroid (MGG Stain)

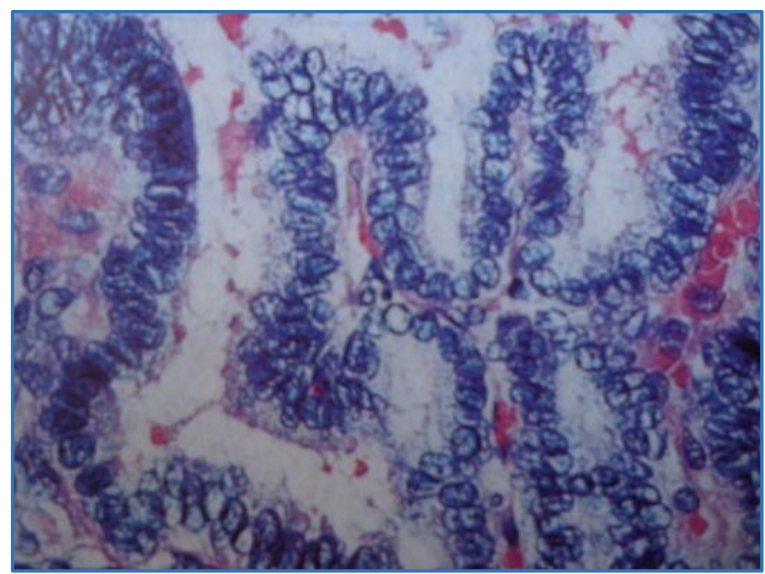

Fig. 5: Photomicrograph showing HPE from Papillary Carcinoma Thyroid (H and E Stain)

\section{DISCUSSION}

Today, FNAC is practiced worldwide for rapid and accurate preoperative diagnosis of thyroid lesions. There are several studies regarding cytological evaluation of thyroid lesions by FNA and literatures claiming the usefulness of thyroid cytology. Out of 100 thyroid lesions in the study, FNA smears of 05 thyroid lesions were inadequate for cytological reporting either due to inadequate aspirated materials or haemorrhagic smears. It is a common problem faced in thyroid FNAC due to high vascularity of the gland.[21]

In all the studies shown in Table 4 (Comparison of Age Range and Mean Age of Patients of Thyroid Lesions with Other Studies), the mean age of patients of thyroid lesions ranged from 36.5 to 46.0 years and our study was most comparable with the studies by Sathiyamurthy K et al 2014,[9]
Silverman JF et al 1986,[22] Arvinthan T et al 2007[23] and Gupta M et al 2010.[24] The abundance of female cases $(87.00 \%)$ in our study also consistent with other reports.

In all the studies shown in Table-5 (Comparison of Nonneoplastic and Neoplastic Thyroid Lesions with Other Studies), the ratio between non-neoplastic and neoplastic lesions of thyroid gland was in between 2.41:1 to 12.29:1. In our study, this ratio was found to be $7.64: 1$, which was well within this range and was similar to the studies by Sathiyamurthy K et al 2014,[9] Silverman JF et al 1986,[22] Godinho-Matos L et al 1992,[25] Handa U et al 2008,[26] Sengupta A et al 2011[27] and Sekhar A et al 2015.[28]

The commonest non-neoplastic thyroid lesions found in this study were goitres (70 thyroid lesions-73.68\%) with or without secondary changes. This was comparable to other studies like Sathiyamurthy K et al 2014,[9] Silverman JF et al 1986[22] and Gupta M et al 2010.[24]

In all the studies shown in Table 6 (Comparison of Diagnostic Accuracy of Thyroid Lesions Cytology with Different Studies), the diagnostic accuracy of thyroid lesions by cytology was about (65-98\%). As our study showed diagnostic accuracy as $93.33 \%$, this was well within this range and was similar to the studies by Gharib H 1994,[3] Bagga PK et al 2010[4] and Likhar KS et al 2013.[12] As per Howlett reported that diagnosis of papillary carcinoma on FNAC is less problematic, in our study it was also proved.

Although, there are a large body of world literatures claiming the accuracy and usefulness of thyroid fine needle aspiration cytology, there are also evidences showing possible limitations and pitfalls of this procedure.[20] Sometime haemorrhagic aspirates give trouble in identifying the morphological details of the cellular outline resulting in the false positive or false negative diagnosis.

\begin{tabular}{|c|c|c|}
\hline Authors & $\begin{array}{l}\text { Age Range } \\
\text { (Years) }\end{array}$ & $\begin{array}{l}\text { Mean Age } \\
\text { (Years) }\end{array}$ \\
\hline Sathiyamurthy K et al 2014[9] & $10-76$ & 36.5 \\
\hline Silverman JF et al 1986[22] & $16-79$ & 44.8 \\
\hline Arvinthan T et al 2007[23] & $26-59$ & 46.0 \\
\hline Gupta M et al 2010[24] & $22-58$ & 38.9 \\
\hline Our study & $7-73$ & 48.9 \\
\hline \multicolumn{3}{|c|}{$\begin{array}{l}\text { Table 4: Comparison of Age Range and Mean Age of } \\
\text { Patients of Thyroid Lesions with Other Studies }\end{array}$} \\
\hline
\end{tabular}

\begin{tabular}{|c|c|c|c|}
\hline Study & $\begin{array}{c}\text { Non- } \\
\text { Neoplastic }\end{array}$ & Neoplastic & Ratio \\
\hline $\begin{array}{c}\text { Sathiyamurthy K et al } \\
\text { 2014[9] }\end{array}$ & 100 & 10 & $10.00: 1$ \\
\hline $\begin{array}{c}\text { Silverman JF et al 1986[22] } \\
\text { Godinho-Matos L et al } \\
1992[25]\end{array}$ & 193 & 80 & $2.41: 1$ \\
\hline Handa U et al 2008[26] & 381 & 31 & $4.91: 1$ \\
\hline Sengupta A et al 2011[27] & 148 & 30 & $4.93: 1$ \\
\hline Sekhar A et al 2015[28] & 118 & 31 & $3.80: 1$ \\
\hline Our Study & 84 & 11 & $7.64: 1$ \\
\hline
\end{tabular}

Table 5: Comparison of Non-Neoplastic and Neoplastic Thyroid Lesions with Other Studies

\begin{tabular}{|c|c|}
\hline Study & Diagnostic Accuracy \\
\hline Gharib H. 1994[3] & $95.00 \%$ \\
\hline Bagga PK et al 2010[4] & $96.20 \%$ \\
\hline Likhar KS et al 2013[12] & $77.78 \%$ \\
\hline Our Study & $93.33 \%$ \\
\hline
\end{tabular}

Table 6: Comparison of Diagnostic Accuracy of Thyroid Lesions Cytology with Different Studies 


\section{CONCLUSION}

FNAC has high sensitivity in cytological diagnosis of thyroid lesions and proper cytological diagnosis may be considered as a primary line of investigation of thyroid lesions and its management. Based on the cytological diagnosis of the thyroid lesions, patients with thyroid lesions may put for surgeries or medical treatments and can decrease the rate of unnecessary thyroid surgeries. This study was a hospitalbased study that described the cytological patterns of thyroid lesions that encountered in this institute within the study period and histopathological diagnosis comparison wherever possible. Due to its high accuracy, sensitivity and specificity, the study established its usefulness for proper line of management of the patients with thyroid lesions. The limitation of the study was that due to absence of representative aspirated materials of 05 thyroid lesions couldn't be diagnosed in the appropriate manner. FNAC diagnoses of only 15 thyroid lesions were available for histopathological study. All patients performed FNAC for thyroid lesions during the study period in our institute couldn't be followed up, probably these patients attended other centres later.

\section{ACKNOWLEDGEMENTS}

The author acknowledges the help and co-operation received from the faculties of ENT and Pathology Department and laboratory technicians of cytopathology and histopathology sections of Pathology Department, Tezpur Medical College and Hospital, Tezpur, Assam, while conducting the present study.

\section{REFERENCES}

1. Sanchez MA, Stahl RE. The thyroid, parathyroid, and neck masses, other lymph nodes. In: Koss LG, ed.Koss' diagnostic cytology and its histopathologic bases. $5^{\text {th }}$ ed. Vol.2.Philadelphia: Lippincott Williams and Wilkins 1148-85.

2. Kini SR. Fine needle aspiration cytology thyroid. In: Mitchell W, ed. Colour atlas of differential diagnosis in exfoliative and aspiration cytopathology. Baltimore: Williams and Wilkins 1999:227.

3. Gharib H. Fine needle aspiration biopsy of thyroid nodules, advantages, limitations, and effect. Mayo Clinic Proc 1994;69(1):44-49.

4. Bagga PK, Mahajan NC. Fine needle aspiration cytology of thyroid swelling. How useful and accurate is it? Indian Journal Cancer 2010;47(4):437-42.

5. Wang C, CrapoLM. The epidemiology of thyroid disease and implication for screening.EndocrinolMetabClin North Am 1997;26(1):189-218.

6. SEER Stat Fact Sheets. Thyroid Cancers 2013.Available from www.cancer.guv.

7. Orell SR. Manual and atlas of fine needle aspiration cytology. In: Orell SR, Sterrett GF, Walters MN, et al, eds. $4^{\text {th }}$ ed. New Delhi: Churchill-Livingstone 2005:125-64.

8. Suen KC. Atlas and textbook of aspiration biopsy cytology. London: Williams and Wilkins 1990:16-41.

9. Sathiyamurthy K, Patil MS, Mirje M. Fine needle aspiration cytology study of thyroid lesions. International Journal of Current Research2014;6(10):9230-3.
10. DeMay RM. The art and science of cytopathology. Aspiration cytology.Vol.2. Chicago: ASCP Press 1996:703-78.

11. Guhamallick M, Sengupta $S$, Bhattacharya NK, et al. Cytodiagnosis of thyroid lesions-usefulness and pitfalls: a study of 288 cases. Journal of Cytology 2016;25(1):6-9. URL:http://www.jcytol.org.

12. Likhar KS, Hazari RA, Gupta SG, et al. Diagnostic accuracy of fine needle aspiration cytology in thyroid lesions. A hospital-based study. Thyroid Res Pract 2013;10(2):6871.

13. Jayaram G, Basu D. Cytology in the diagnosis of thyroid lesions: a review. JAPI 1993;41(3):164-9.

14. DeGrootLJ, Reilly M, Pinnamenemi K, et al. Retrospective and prospective study of radiation-induced thyroid disease. Am J Med 1983;74(5):852-62.

15. Belfiore A,La Rosa GL,La PortaGA, et al. Cancer risk in patients with cold thyroid nodules: relevance of iodine intake, sex, age, and multinodularity. Am J Med 1992;93(4):363-9.

16. Gharib H, Goellner JR. Evaluation of nodular thyroid disease. EndocrinolMetabClin North Am 1988;17(3):511-26.

17. Mazzaferri EL, de los Santos ET, Rofagha-Keyhani S. Solitary thyroid nodules: diagnosis and management. Med Clin North Am 1988;72(5):1177-211.

18. Frable WJ. The treatment of thyroid cancer: the role of fine needle aspiration cytology. Arch Otolaryingol Head Neck Surg 1986;112(11):1200-3.

19. Caruso D, Mazzaferri EL. Fine needle aspiration biopsy in the management of thyroid nodules. Endocrinologist 1991;1(3):194-202.

20. John D. Bancroft and Marilyn Gamble. Theory and practice of histological techniques. $5^{\text {th }}$ edn. Edinburgh: Churchill Livingstone 2002.

21. Hall TL, Layfield LJ, Philippe A, et al. Sources of diagnostic error in fine needle aspiration of thyroid. Cancer 1989;63(4):718-25.

22. Silverman JF, West RL, Larkin EW, et al. The role of fine needle aspiration biopsy in the rapid diagnosis and management of thyroid neoplasm. Cancer 1986;57(6):1164-70.

23. Arvinthan T, Banagala ASK, Gamage KJPK. Use of fine needle aspiration cytology on thyroid lumps. Galle Medical Journal 2007;12(1):25-7.

24. Gupta M, Gupta S, Gupta VB. Correlation of fine needle aspiration cytology with histopathology in the diagnosis of solitary thyroid nodule. Journal of Thyroid Research Article ID 379051, 2010:2010.

25. Godinho-Matos L, Kocjan G, Kurtz A. Contribution of fine needle aspiration cytology to diagnosis and management of thyroid disease. J ClinPathol 1992;45(5):391-5.

26. Handa U, Garg S, Mohan $\mathrm{H}$, et al. Role of fine needle aspiration cytology in diagnosis and management of thyroid lesions: a study on 434 patients. J Cytol 2008;25(1):13-7.

27. Sengupta A, Pal R, Kar S, et al. Fine needle aspiration cytology as the primary diagnostic tool in thyroid enlargement. J Nat ScBiol Med 2011;2(1):113-8.

28. Sekhar A, Inamdae SS, Dombale VD, et al. Fine needle aspiration cytology study of thyroid lesions-a 2-year prospective study in a tertiary centre. Int J of Pharma and BiolSc 2015;3:15-19 